\title{
RESEARCH
}

\section{Glutamine-induced signaling pathways via amino acid receptors in enteroendocrine $L$ cell lines}

\author{
Takumi Nakamura1,2,*, Kazuki Harada1,*, Taichi Kamiya1,*, Mai Takizawa1, Jim Küppers³, Kazuo Nakajima², \\ Michael Gütschow³ ${ }^{3}$ Tetsuya Kitaguchi ${ }^{4}$, Kunihiro Ohta ${ }^{1}$, Tadafumi Kato ${ }^{2}$ and Takashi Tsuboi ${ }^{1}$
}

1Department of Life Sciences, Graduate School of Arts and Sciences, The University of Tokyo, Meguro, Tokyo, Japan 2Laboratory for Molecular Dynamics of Mental Disorders, RIKEN Center for Brain Science, Wako-shi, Saitama, Japan 3Pharmaceutical Chemistry I, Pharmaceutical Institute, University of Bonn, Bonn, Germany

${ }^{4}$ Laboratory for Chemistry and Life Science, Institute of Innovative Research, Tokyo Institute of Technology, Yokohama, Kanagawa, Japan

Correspondence should be addressed to T Tsuboi: takatsuboi@bio.c.u-tokyo.ac.jp

*(T Nakamura, K Harada and T Kamiya contributed equally to this work)

\begin{abstract}
Glucagon-like peptide-1 (GLP-1), secreted by gastrointestinal enteroendocrine $L$ cells, induces insulin secretion and is important for glucose homeostasis. GLP-1 secretion is induced by various luminal nutrients, including amino acids. Intracellular $\mathrm{Ca}^{2+}$ and CAMP dynamics play an important role in GLP-1 secretion regulation; however, several aspects of the underlying mechanism of amino acid-induced GLP-1 secretion are not well characterized. We investigated the mechanisms underlying the L-glutamine-induced increase in $\mathrm{Ca}^{2+}$ and cAMP intracellular concentrations ([Ca $\left.{ }^{2+}\right]_{\mathrm{i}}$ and $[\mathrm{CAMP}]_{\mathrm{i}}$, respectively) in murine enteroendocrine L cell line GLUTag cells. Application of L-glutamine to cells under low extracellular $\left[\mathrm{Na}^{+}\right]$conditions, which inhibited the function of the sodium-coupled L-glutamine transporter, did not induce an increase in $\left[\mathrm{Ca}^{2+}\right]_{\mathrm{i}}$. Application of $\mathrm{G}$ proteincoupled receptor family $C$ group 6 member $A$ and calcium-sensing receptor antagonist showed little effect on $\left[\mathrm{Ca}^{2+}\right]_{i}$ and [CAMP]; however, taste receptor type 1 member 3 (TAS1R3) antagonist suppressed the increase in [CAMP] $]_{i}$. To elucidate the function of TAS1R3, which forms a heterodimeric umami receptor with taste receptor type 1 member 1 (TAS1R1), we generated TAS1R1 and TAS1R3 mutant GLUTag cells using the CRISPR/ Cas9 system. TAS1R1 mutant GLUTag cells exhibited L-glutamine-induced increase in [CAMP $]_{i}$, whereas some TAS1R3 mutant GLUTag cells did not exhibit L-glutamine-induced increase in $[C A M P]_{i}$ and GLP-1 secretion. These findings suggest that TAS1R3 is important for L-glutamine-induced increase in [CAMP] $]_{i}$ and GLP-1 secretion. Thus, TAS1R3 may be coupled with $\mathrm{G}_{\mathrm{s}}$ and related to cAMP regulation.
\end{abstract}

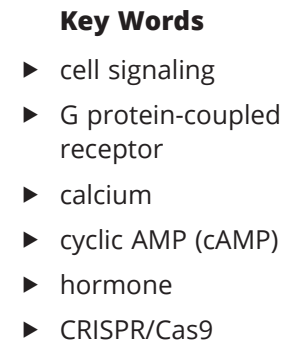

Journal of Molecular Endocrinology (2020) 64, 133-143

\section{Introduction}

Glucagon-like peptide-1 (GLP-1) is a member of the incretin family and is secreted by the gastrointestinal endocrine $\mathrm{L}$ cells (Harada et al. 2017, 2018a,b, Drucker 2018). GLP-1 regulates the increase in insulin secretion from the pancreatic $\beta$ cells (Lamont et al. 2012, Smith et al. 2014) and suppresses glucagon secretion from the pancreatic $\alpha$ cells, which helps control blood glucose concentration (de Heer et al. 2008, Richards et al. 2014). Thus, GLP-1 receptor agonists and GLP-1 protease inhibitors are used for achieving glycemic control, especially in patients 
with type 2 diabetes mellitus (T2DM) (Eng et al. 1992, Villhauer et al. 2003, Drucker et al. 2017). Indeed, a genome-wide association study identified a significant missense variant of GLP-1 receptor in patients with T2DM $\left(P=6.10 \times 10^{-14}, 36,614\right.$ cases and 155,150 controls of Japanese ancestry) (Suzuki et al. 2019). Furthermore, neural transmission initiated by GLP-1 signaling reduces food intake (Rodriquez de Fonseca et al. 2000, Hsu et al. 2018). Despite the importance of GLP-1 for appetite regulation and treatment of T2DM, the precise mechanism of GLP-1 secretion remains unclear.

Recent studies have shown that luminal nutrients (including glucose, fatty acids, and amino acids) induce GLP-1 secretion from the L cells (Tolhurst et al. 2012, Feng et al. 2013, Oya et al. 2013). Glucose-induced GLP-1 secretion depends on the depolarization triggered by $\mathrm{Na}^{+}$ influx via the sodium-dependent glucose transporter-1 (SGLT-1) and $\mathrm{K}^{+}$efflux via ATP-sensitive $\mathrm{K}^{+}\left(\mathrm{K}_{\text {ATP }}\right)$ channels (Reimann et al. 2008). The depolarization triggers the opening of voltage-gated $\mathrm{Ca}^{2+}$ channels and induces GLP-1 secretion (Gribble et al. 2003, Reimann et al. 2008, Diakogiannaki et al. 2012). Indeed, the glucose-induced $\mathrm{Ca}^{2+}$ response and GLP-1 secretion are impaired in Sglt1 -knockout mice. The sweet receptor is another regulator of glucose-induced GLP-1 secretion (Margolskee et al. 2007). This receptor is a heterodimer composed of taste receptor type 1 member 2 (TAS1R2) and member 3 (TAS1R3). Fatty acid-induced GLP-1 secretion is regulated by the pathways of $G$ protein-coupled receptors (GPCRs) (Janssen \& Depoortere 2013). Increase in the intracellular concentrations of $\mathrm{Ca}^{2+}\left(\left[\mathrm{Ca}^{2+}\right]_{\mathrm{i}}\right)$ and cAMP $\left([\mathrm{cAMP}]_{\mathrm{i}}\right)$ triggered via $G_{q}$ proteins and $G_{s}$ proteins, respectively, is the key mechanism of nutrient-induced GLP-1 secretion.

A recent study investigated the effect of various amino acids on GLP-1 secretion using mouse primary cultured small intestinal cells; the authors found that L-glutamine had the greatest effect GLP-1 secretion (Tolhurst et al. 2011). However, the precise molecular mechanism of L-glutamine-induced GLP-1 secretion remains unclear. In the present study, we used GLUTag cell lines derived from mouse gastrointestinal endocrine L cells and found that L-glutamine, among various other amino acids, increased both $\left[\mathrm{Ca}^{2+}\right]_{\mathrm{i}}$ and $[\mathrm{cAMP}]_{\mathrm{i}}$, and induced GLP-1 secretion.

To elucidate the molecular mechanisms of L-glutamine-induced GLP-1 secretion, we first examined the contribution of sodium-coupled L-glutamine transporters. We found that the L-glutamine-induced $\left[\mathrm{Ca}^{2+}\right]_{\mathrm{i}}$ increase was suppressed. We next investigated the relationship between L-glutamine-induced GLP-1 secretion and amino acid-sensitive GPCRs
(Wellendorph et al. 2009), such as G protein-coupled receptor class C group 6 member A (GPRC6A), calciumsensing receptor (CaSR), TAS1R1, and TAS1R3. We found no significant involvement of GPRC6A and CaSR in the increase of $\left[\mathrm{Ca}^{2+}\right]_{\mathrm{i}}$ and $[\mathrm{CAMP}]_{\mathrm{i}}$. Furthermore, a TAS1R3 antagonist partially suppressed the increase in $[\mathrm{CAMP}]_{\mathrm{i}}$, suggesting the role of an unknown signaling pathway downstream of TAS1R3. To confirm the contribution of TAS1R3 on $[\mathrm{cAMP}]_{\mathrm{i}}$ elevation, we generated and analyzed TAS1R3homozygous mutant GLUTag cells using the CRISPR/Cas9 system. Two of the three TAS1R3 mutant GLUTag cell lines showed no significant L-glutamine-induced $[\mathrm{cAMP}]_{\mathrm{i}}$ elevation. These findings indicate that L-glutamineinduced GLP-1 secretion from GLUTag cells was triggered by the increase in intracellular cAMP via TAS1R3.

\section{Materials and methods}

\section{Chemicals}

L-glutamine, L-asparagine monohydrate, L(-)-phenylalanine, L-leucine, and L-arginine were purchased from Nacalai Tesque (Kyoto, Japan). L-glutamate potassium monohydrate, L-alanine, L-tryptophan, NPS-2143, and lactisole were purchased from Sigma-Aldrich. Glycine, L(+)-lysine monohydrochloride, forskolin (Fsk), and BSA were purchased from FUJIFILM Wako Pure Chemical Institute (Osaka, Japan).

\section{Cell culture and transfection}

GLUTag cells were cultured in Dulbecco's modified Eagle's medium (Sigma-Aldrich) supplemented with $1 \mathrm{~g} / \mathrm{L}$ glucose, L-glutamine, sodium pyruvate, $10 \%$ (v/v) heat-inactivated fetal bovine serum (Sigma-Aldrich), $100 \mathrm{U} / \mathrm{mL}$ penicillin, and $100 \mu \mathrm{g} / \mathrm{mL}$ streptomycin (Sigma-Aldrich), at $37^{\circ} \mathrm{C}$ in an atmosphere of $5 \% \mathrm{CO}_{2}$. For imaging experiments, the cells were trypsinized and $1-1.5 \times 10^{5}$ cells were added to poly-L-lysine (Sigma-Aldrich)-coated glass coverslips in $35 \mathrm{~mm}$ dishes. Two days after plating, the cells were transfected with $1.5 \mu \mathrm{g}$ of Flamindo2 plasmid using $2 \mu \mathrm{L}$ of X-treme GENE HP DNA Transfection Reagent (Roche) according to the manufacturer's protocol. The medium was exchanged $8 \mathrm{~h}$ after transfection and the cells were cultured at $30-32^{\circ} \mathrm{C}$ for 2 days until imaging. For establishment of mutant GLUTag cell lines, $2.5 \times 10^{5}$ cells were plated in the wells of a six-well plate 1 day prior to transfection. The cells were transfected with $1.5 \mu \mathrm{g}$ of single guide RNA-Streptococcus pyogenes Cas9-green fluorescent protein (sgRNA-SpCas9-GFP) 
all-in-one vectors using $3.0 \mu \mathrm{L}$ of Lipofectamine 2000 (Thermo Fisher Scientific).

\section{RNA isolation and RT-PCR analysis}

Total RNA from GLUTag cells and mouse brain was isolated using the RNeasy Mini Kit (QIAGEN). After DNase treatment using RNase-Free DNase Set (QIAGEN), cDNA was synthesized using the High Capacity RNA-to-cDNA Kit (Thermo Fisher Scientific). The synthesized cDNA was amplified using the EmeraldAmp PCR Master Mix (TaKaRa Bio). For PCR amplification of Casr (NM_013803), the forward primer 5'-AGCAGGTGACCTTCGATGAGT-3' and the reverse primer 5'-ACTTCCTTGAACACAATGGAGC-3' were used. For Gprc6a (NM_153071), the forward primer 5'-CGGGATCCAGACGACCACAAATCCAG-3' and the reverse primer 5'-CCAAGCTTGATTCATAACTCACC TGTGGC-3' were used. For Tas1r1 (NM_031867), the forward primer 5'-GCAGAGAGATCTTCGCAACCA-3' and the reverse primer 5'-TACTTATCGCTGGGGATGGTG-3' were used. For Tas1r3 (NM_031872), the forward primer 5'-GAACATGTGATGGGGCAACG-3' and the reverse primer 5'-GTAGGGTGTTGTGAAGGGCT-3' were used. For glyceraldehyde 3-phosphate dehydrogenase (GAPDH, NM_001289726), the forward primer 5'-CCGGTGCTG AGTATGTCGTGGAGTCTAC-3' and the reverse primer 5'-CTTTCCAGAGGGGCCATCCACAGTCTTC-3' were used.

\section{Visualization of $\left[\mathrm{Ca}^{2+}\right]_{\mathrm{i}}$ and cAMP dynamics}

For $\mathrm{Ca}^{2+}$ imaging, GLUTag cells plated on coverslips for 2 days were loaded with $2.5 \mu \mathrm{M}$ Fluo-3 AM (Dojindo, Kumamoto, Japan) in modified Ringer Buffer (RB: $140 \mathrm{mM}$ $\mathrm{NaCl}, 3.5 \mathrm{mM} \mathrm{KCl}, 0.5 \mathrm{mM} \mathrm{NaH}_{2} \mathrm{PO}_{4}, 0.5 \mathrm{mM} \mathrm{MgSO}_{4}, 1.5$ $\mathrm{mM} \mathrm{CaCl}, 10 \mathrm{mM}$ HEPES, $2 \mathrm{mM} \mathrm{NaHCO}_{3}$ ) containing 5 $\mathrm{mM}$ glucose. After incubation for $20 \mathrm{~min}$ at $37^{\circ} \mathrm{C}$ in an atmosphere of $5 \% \mathrm{CO}_{2}$, the cells were washed twice, added to RB containing $0.1 \mathrm{mM}$ glucose, and mounted on a stage maintained at $37^{\circ} \mathrm{C}$. For cAMP imaging, GLUTag cells expressing Flamindo 2 were washed and imaged in RB.

Imaging was performed using an inverted microscope (ECLIPSE Ti-E; Nikon) equipped with an oilimmersion objective lens (CFI Plan Fluor, 40×, numerical aperture =1.30; Nikon) and an EM-CCD camera (iXon, Andor, Belfast, UK), whose exposure was controlled by MetaMorph software (Molecular Devices, Sunnyvale, CA, USA). Images were acquired using a mercury lamp (Nikon) using a filter set with 465-495 nm excitation filter, $505 \mathrm{~nm}$ dichroic mirror, and 515-555 nm emission filter (Nikon). Images were acquired every $5 \mathrm{~s}$ for $10 \mathrm{~min}$, and L-glutamine stimulation was performed with a pipette $180 \mathrm{~s}$ after the initiation of image acquisition. High $\left[\mathrm{K}^{+}\right]$treatment was performed by perfusing a solution containing 83.6 $\mathrm{mM} \mathrm{NaCl}, 50 \mathrm{mM} \mathrm{KCl}, 0.5 \mathrm{mM} \mathrm{NaH}_{2} \mathrm{PO}_{4}, 0.5 \mathrm{mM} \mathrm{MgSO}_{4}$, $1.5 \mathrm{mM} \mathrm{CaCl}_{2}, 10 \mathrm{mM}$ HEPES, $2 \mathrm{mM} \mathrm{NaHCO}$, and $0.1 \mathrm{mM}$ glucose.

The acquired images were aligned using 'Stackreg' plugin in ImageJ (National Institutes of Health), and the fluorescence intensity of the cells was quantified using the MetaMorph software. The fluorescence intensity in the background of acquired images was calculated as zero. After subtracting the background, basal fluorescence intensity, normalized to $100 \%$, was calculated as the average fluorescence intensity between 150 and $180 \mathrm{~s}$ after initiation of image acquisition. For $\mathrm{Ca}^{2+}$ imaging, cells which showed excessive oscillation by over $40 \%$ of basal fluorescence intensity (before stimulation) were excluded from further analysis, and the peak amplitude of normalized fluorescence intensity after stimulation was compared. For cAMP imaging, cells that constantly exhibited an increase or decrease in fluorescence intensity before stimulation were excluded from further analysis. To distinguish between transient decrease in fluorescence intensity caused by $\mathrm{pH}$ changes and long-lasting decrease in fluorescence intensity caused by cAMP elevation, the area under the curve (AUC) was calculated as the summary of normalized fluorescence intensity between 185 and $600 \mathrm{~s}$ after the initiation of image acquisition. To assess whether the basal fluorescence intensity of Fluo3 and Flamindo2 affects the kinetics of the indicators, we investigated the correlation between the basal fluorescence intensity and the response to L-glutamine and found no significant correlation (Supplementary Fig. 1, see section on supplementary materials given at the end of this article).

\section{Enzyme-linked immunosorbent assay}

GLUTag cells were plated in six-well plates at $0.5 \times 10^{6}$ cells per well. Two days after plating, cells were washed twice with RB containing $0.1 \mathrm{mM}$ glucose and $0.5 \%(\mathrm{w} / \mathrm{v})$ BSA (FUJIFILM Wako Pure Chemical Institute). The washed cells were incubated in $1 \mathrm{~mL}$ of $\mathrm{RB}$ with $5 \mathrm{mM}$ glucose, $0.5 \%(\mathrm{w} / \mathrm{v}) \mathrm{BSA}, 1 \%(\mathrm{v} / \mathrm{v})$ dipeptidyl peptidase 4 inhibitor (Merck Millipore), and $500 \mu \mathrm{M} \mathrm{L}$-glutamine for $3 \mathrm{~h}$ at $37^{\circ} \mathrm{C}$ in an atmosphere of $5 \% \mathrm{CO}_{2}$. After centrifugation at $1000 \mathrm{~g}$ for $10 \mathrm{~min}$ at $4^{\circ} \mathrm{C}$, the amount of GLP-1 in the supernatant was measured using the Glucagon-Like Peptide-1 (Active) ELISA Kit (Merck Millipore) and a microplate reader (Varioskan LUX; Thermo Fisher Scientific). 


\section{Inhibition experiments}

Low $\left[\mathrm{Na}^{+}\right]$treatment was performed using a solution containing $140 \mathrm{mM}$ N-methyl-D-glucamine, $3.5 \mathrm{mM} \mathrm{KCl}$, $0.5 \mathrm{mM} \mathrm{NaH}_{2} \mathrm{PO}_{4}, 0.5 \mathrm{mM} \mathrm{MgSO}_{4}, 1.5 \mathrm{mM} \mathrm{CaCl}_{2}, 10 \mathrm{mM}$ HEPES, $2 \mathrm{mM} \mathrm{NaHCO}$, and $0.1 \mathrm{mM}$ glucose. BIM-46187 was applied at $25 \mu \mathrm{M}$ in serum-free medium for $2 \mathrm{~h}$ prior to imaging. NPS-2143 was applied simultaneously with glutamine at $3 \mu \mathrm{M}$. Lactisole was applied at $3 \mathrm{mM}$ in $\mathrm{RB}$ for 30 min before the experiments, and constantly applied in the RB during imaging. The same concentration of $0.1 \%(\mathrm{v} / \mathrm{v})$ dimethyl sulfoxide was added in the control RB upon application of NPS-2143 and lactisole.

\section{Plasmid construction}

We generated the sgRNA-SpCas9-GFP all-in-one vectors using pSpCas9(BB)-2A-GFP (PX458) plasmid, as described in our previous work (Nakamura et al. 2018). The sequence of inserted sgRNA was as follows: the forward primer, 5'-caccgCGTCATACAGTTCATACCCC-3'; the reverse primer, 5'-aaacGGGGTATGAACTGTATGACGc-3' for Tas1r1 and the forward primer, 5'-caccg TCTAGTCTGGCCAATGCACG-3'; the reverse primer, 5'-aaacCGTGCATTGGCCAGACTAGAc-3' for Tas1r3. The genome cleavage activity of the vectors was validated by the Surveyor assay using the Surveyor Mutation Detection Kit (Integrated DNA Technologies, Coralville, IA, USA). PCR fragments were amplified by the PCR conditions shown in Supplementary Table 1A using TaKaRa LA Taq (TaKaRa Bio).

\section{Preparation of conditioned culture medium}

The supernatant of the medium used to grow confluent GLUTag cells was collected and centrifuged for $5 \mathrm{~min}$ at $500 \boldsymbol{g}$ to exclude contaminants, followed by sterilization using a $0.22-\mu \mathrm{m}$ filter (Merck Millipore). The sterilized supernatant was diluted 10 -fold using the culture medium.

\section{Establishment of TAS1R1- or TAS1R3- $\Delta$ C GLUTag cells using CRISPR/Cas9}

We previously reported the detailed protocol for establishing mutant cell lines using the CRISPR/Cas9 system (Nakamura et al. 2018). Briefly, the transfected cells in 6-well plates were trypsinized and collected by a suspension buffer for fluorescence-activated cell sorting in 2\% FBS, $0.02 \mathrm{M}$ glucose, and $1 \times$ penicillin and streptomycin diluted with $1 \times$ phosphate buffered saline. The collected cells were exposed to 7-amino actinomycin D (7-AAD; BD Biosciences, San Jose, CA, USA) to distinguish dead cells (5 $\mu \mathrm{L}$ per $1.0 \times 10^{6}$ cells). GFP (+) and 7-AAD (-) GLUTag cells were single cell-sorted into wells of 96-well plates containing $200 \mu \mathrm{L}$ of conditioned culture medium using a FACSAria apparatus (BD Biosciences).

After single cell sorting (day 0), the plates were placed in an incubator $\left(37^{\circ} \mathrm{C}\right.$ and $\left.5 \% \mathrm{CO}_{2}\right)$ and incubated statically until day 5 . At that time, growth of a few cells was evident. One hundred microliters of conditioned medium were added to each well. The medium was changed every 4-5 days until adequate growth of the colonies. On day 20 , the colonies were split by pipetting and transferred to new 96-well plates. Upon achieving confluent growth, the cells were transferred to wells of a 24-well plate for scale-up and to wells of a 96-well plate for genotyping. Each clone was grown to confluence in $10 \mathrm{~cm}$ dish and frozen with $1 \mathrm{~mL}$ of Cell Banker 1 Plus (NIPPON ZENYAKU KOGYO, Fukushima, Japan).

\section{Crude PCR for genotyping of mutant GLUTag cells}

GLUTag cells cultured in wells of 96-well plates were exposed to $50 \mu \mathrm{L}$ of lysis buffer for crude PCR $(10 \mathrm{mM}$ Tris- $\mathrm{HCl}(\mathrm{pH} 8.0), 0.1 \%(\mathrm{v} / \mathrm{v})$ Triton-X, $10 \mathrm{mM}$ EDTA, and $1 / 100$ diluted proteinase $\mathrm{K}$ ) at $37^{\circ} \mathrm{C}$ overnight. One microliter aliquots of the ten-fold diluted crude cell lysates were added to $10 \mu \mathrm{L}$ scale of PCR mix containing LA Taq polymerase (TaKaRa Bio). PCR fragments were amplified by the same conditions used for the Surveyor assay and sequenced using primer No.1 (Tas1r3) and primer No.3 (Tas1r3) (Supplementary Table 1A). Off-target mutation analyses were performed using the PCR conditions shown in Supplementary Table 1B using PrimeSTAR GXL DNA polymerase (TaKaRa Bio). We extracted genome DNA of the mutant GLUTag cells using DNeasy Blood \& Tissue Kits (QIAGEN), according to manufacturer's protocol, to validate the insertion of Cas9 plasmid. The primers used to amplify GFP region were as follows: forward primer, 5'-GACGACGGCAACTACAAGAC-3'; reverse primer, 5'-GTGCTCAGGTAGTGGTTGTC-3'.

Owing to the detection of GFP bands in several lines, we assessed those cells for the presence or absence of GFP fluorescence. Three days after plating onto glass coverslips, the cells were examined with an inverted microscope (IX71 , Olympus) equipped with an objective lens (UPlanApo, $20 \times, \mathrm{NA}=0.70$, Olympus) and an EM-CCD camera (Evolve, Photometrics, Tucson, AZ, US). Images were acquired using a xenon lamp, 460-495 nm excitation filter, 505 $\mathrm{nm}$ dichroic mirror, and 510-555 nm emission filter 
(Olympus). The exposure time of the EM-CCD camera was controlled by the MetaMorph software.

As positive control, cells were transfected with $1.5 \mu \mathrm{g}$ of pEGFP-C1 or $3 \mu \mathrm{g}$ of pSpCas9(BB)-2A-GFP plasmids using $3 \mu \mathrm{L}$ of Lipofectamine 2000 Transfection Reagent (Thermo Fisher Scientific) 2 days after plating, as recommended by the manufacturer. The medium was exchanged $8 \mathrm{~h}$ after transfection and the cells were cultured for 1 day until imaging.

\section{Statistical analyses}

Between-group differences were assessed using the twosided Welch's $t$ test with Bonferroni correction or one-way ANOVA with Dunnett or Tukey's multiple comparison test. The GraphPad Prism 6 software (GraphPad Software) was used for all statistical analyses.

\section{Results}

\section{L-glutamine increases both intracellular $\mathrm{Ca}^{2+}$ and cAMP levels, and induces GLP-1 secretion}

We first examined the effect of exposure of GLUTag cells to various amino acids $(500 \mu \mathrm{M})$ on the $\left[\mathrm{Ca}^{2+}\right]_{\mathrm{i}}$ and $[\mathrm{cAMP}]_{\mathrm{i}}$ levels. Live cell imaging analysis was performed using the $\mathrm{Ca}^{2+}$-sensitive dye, Fluo3, and the genetically encoded cAMP indicator, Flamindo2 (Odaka et al. 2014). Flamindo2 is an intensiometric cAMP indicator; it exhibits a decrease in fluorescence intensity upon binding to cAMP. A previous study has used the FRET-based cAMP indicator epac2-camps in GLUTag cells (Friedlander et al. 2011). The basal CFP/YFP ratio was approximately 1.0, which corresponds to $400 \mathrm{nM}$ of cAMP (Nikolaev et al. 2004). The $\mathrm{EC}_{50}$ value of Flamindo2 is $3.2 \mu \mathrm{M}$; therefore, it is appropriate for monitoring L-glutamine-induced increase in cAMP level in GLUTag cells. L-glutamine, L-asparagine, L-alanine, L-glycine, and L-arginine induced an increase in the fluorescence intensity of Fluo3 (Fig. 1A). Only L-glutamine induced a decrease in the area under curve (AUC) of the 10-min kinetics in the fluorescence intensity of Flamindo2, whereas L-glutamate, L-arginine, and L-lysine increased the AUC (Fig. 1B). Because the fluorescence intensity of Flamindo2 decreases upon binding to cAMP, the data indicated that L-glutamine increases $[\mathrm{CAMP}]_{\mathrm{i}}$, whereas L-glutamate, L-arginine, and L-lysine decrease $[\mathrm{CAMP}]_{\mathrm{i}}$. Based on these results, we concluded that L-glutamine increased both $\left[\mathrm{Ca}^{2+}\right]_{\mathrm{i}}$ and $[\mathrm{cAMP}]_{\mathrm{i}}$ in GLUTag cells. Higher concentration of L-glutamine induced a greater increase in $\left[\mathrm{Ca}^{2+}\right]_{\mathrm{i}}$ and $[\mathrm{cAMP}]_{\mathrm{i}}$ levels (Supplementary Fig. 2). As compared to positive controls (high $\left[\mathrm{K}^{+}\right]$solution which induces membrane depolarization for $\mathrm{Ca}^{2+}$, and $10 \mu \mathrm{M}$ of adenylyl cyclase activator forskolin (Fsk) for cAMP), L-glutamine induced a weaker response (Supplementary Fig. 3). To validate whether L-glutamine induces GLP-1 secretion, we quantified GLP-1 after L-glutamine treatment using ELISA. L-glutamine significantly increased the amount of GLP-1 secreted by GLUTag cells (Fig. 1C).

\section{Sodium-coupled L-glutamine transporter and amino acid-sensitive GPCRs are involved in L-glutamine-induced increase in $\left[\mathrm{Ca}^{2+}\right]_{\mathrm{i}}$}

Several putative $\mathrm{Ca}^{2+}$ sources have been implicated in L-glutamine-induced GLP-1 secretion. Uptake of L-glutamine by the cytosol together with $\mathrm{Na}^{+}$via sodiumcoupled L-glutamine transporters causes an increase in intracellular $\mathrm{Na}^{+}$levels, which induces membrane depolarization and $\mathrm{Ca}^{2+}$ influx through voltage-dependent $\mathrm{Ca}^{2+}$ channels (VDCCs). To examine the involvement of sodium-coupled L-glutamine transporters, we applied L-glutamine to GLUTag cells in a solution containing low $\left[\mathrm{Na}^{+}\right]$. Treatment with low $\left[\mathrm{Na}^{+}\right]$significantly suppressed the L-glutamine-induced increase in $\left[\mathrm{Ca}^{2+}\right]_{\mathrm{i}}$ (Fig. 1D and E). However, $[\mathrm{CAMP}]_{\mathrm{i}}$ increase was not inhibited but enhanced by treatment with low $\left[\mathrm{Na}^{+}\right]$(Fig. $1 \mathrm{~F}$ and $\mathrm{G}$ ); this was due to the lower recovery of the Flamindo2 signal in the low $\left[\mathrm{Na}^{+}\right]$condition after $400 \mathrm{~s}$. We speculated that the low $\left[\mathrm{Na}^{+}\right]$condition did not alter $[\mathrm{CAMP}]_{i}$ generation but did alter cAMP turnover. These results suggested the contribution of sodium-coupled L-glutamine transporters to the L-glutamine-induced increase in $\left[\mathrm{Ca}^{2+}\right]_{\mathrm{i}}$ level.

In addition to sodium-coupled L-glutamine transporters, L-glutamine can activate amino acidsensitive GPCRs and can mobilize $\mathrm{Ca}^{2+}$ from the endoplasmic reticulum via the $G_{q}$ signaling pathway. We thus examined the expression profile of putative amino acid-sensitive GPCRs. Reverse-transcription PCR (RT-PCR) was performed to assess the mRNA expressions of Casr, Gprc6a, Tas1r1, and Tas1r3 (Supplementary Fig. 4A). First, we applied the pan-G protein inhibitor, BIM-46187, with L-glutamine (Ayoub et al. 2009) and found that BIM-46187 significantly suppressed the L-glutamine-induced increase in both $\left[\mathrm{Ca}^{2+}\right]_{\mathrm{i}}$ and $[\mathrm{CAMP}]_{\mathrm{i}}$ levels (Supplementary Fig. 4B, C, D and E). We next utilized NPS-2143 (an antagonist for CaSR and GPRC6A) with L-glutamine. However, NPS-2143 did not suppress the L-glutamine-induced increase in $\left[\mathrm{Ca}^{2+}\right]_{i}$ but showed a mild effect on $[\mathrm{cAMP}]_{i}$ (Fig. 2A, B, C and D). These findings suggested that the 


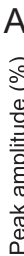

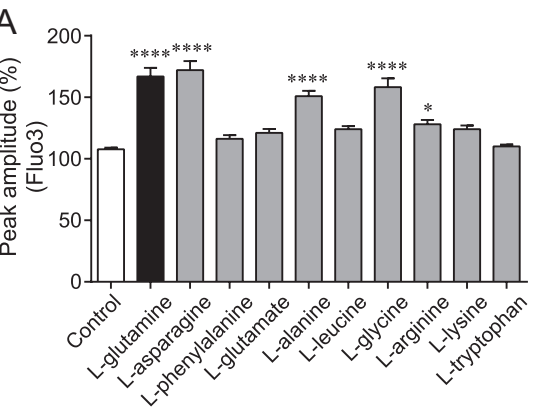

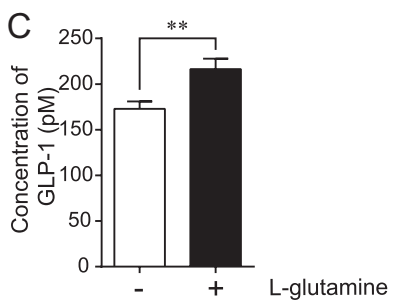
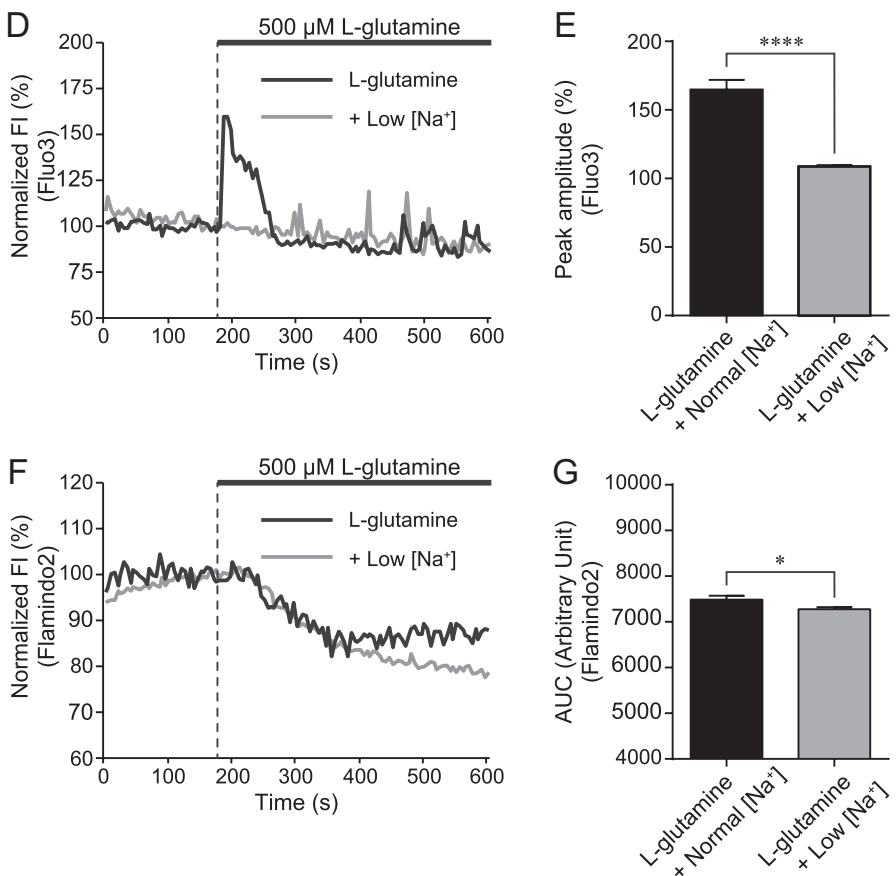

Figure 1

Effect of L-glutamine on intracellular $\mathrm{Ca}^{2+}$ and CAMP dynamics in GLUTag cells and the involvement of sodium-dependent L-glutamine transporters. (A) Peak amplitude calculated from the fluorescence intensity (FI) of Fluo3 after application of various amino acids; $N \geq 17$ cells from $\geq 3$ independent experiments. One-way ANOVA and Dunnett's multiple comparison test. (B) Area under the curve (AUC) calculated from the Fl of Flamindo 2 using various amino acids: $N \geq 17$ cells from $\geq 3$ independent experiments. One-way ANOVA and Dunnett's multiple comparison test. (C) Results of ELISA showing the amount of GLP-1 secreted by GLUTag cells after application of $500 \mu \mathrm{M} \mathrm{L-glutamine.} \mathrm{The} \mathrm{data} \mathrm{are}$ from seven trials from two experiments; Welch's $t$ test. (D) Typical time course of Fl of Fluo3 during application of $500 \mu \mathrm{M} \mathrm{L-glutamine} \mathrm{in} \mathrm{low}$ [Na+]-containing solution. (E) Peak amplitude calculated from the Fl of Fluo3 by application of $500 \mu \mathrm{M}$ L-glutamine in low $\left[\mathrm{Na}^{+}\right]$-containing solution; $\mathrm{N} \geq 23$ cells from three independent experiments; Welch's $t$ test. (F) Typical time course of Fl of Flamindo2 during application of $500 \mu \mathrm{M}$ L-glutamine in low $\left[\mathrm{Na}^{+}\right]$-containing solution. (G) Area under curve $(A \cup C$ ) calculated from the $\mathrm{Fl}$ of Flamindo2 by application of $500 \mu \mathrm{M}$ L-glutamine in low [ $\left.\mathrm{Na}^{+}\right]$-containing solution; $\mathrm{N} \geq 17$ cells from three independent experiments; Welch's $t$ test. Data presented as mean \pm S.E.M. $* P<0.05$ $\star \star P<0.01 ; * \star * x<0.001 ; * \star \star \star * P<0.0001$.
L-glutamine-induced increase in $\left[\mathrm{Ca}^{2+}\right]_{\mathrm{i}}$ was independent of $\mathrm{G}_{\mathrm{q}}$-coupled CaSR and GPRC6A.

\section{TAS1R3 is involved in L-glutamine-induced cAMP production}

TAS1R1 and TAS1R3 act as a heterodimer and form the umami receptor. To investigate the role of TAS1R1 and TAS1R3, GLUTag cells were treated with lactisole. This TAS1R3 inhibitor was recently shown to inhibit human and murine TAS1R3 (Hamano et al. 2015). Interestingly, lactisole had little effect on the $\left[\mathrm{Ca}^{2+}\right]_{\mathrm{i}}$ but significantly suppressed L-glutamine-induced increase in $[\mathrm{CAMP}]_{i}$
(Fig. 2E, F, G and H). Because the umami receptor is coupled with gustducin, which inhibits cAMP production, this result suggested the existence of an uncanonical signaling pathway via TAS1R1 or TAS1R3.

To explore this, we established homozygous TAS1R1or TAS1R3- $\mathrm{C}$ terminal deletion $(\Delta \mathrm{C})$ GLUTag cell lines using CRISPR/Cas9 (Fig. 3). First, we checked the insertion of the Cas9-GFP plasmid into genome DNA to exclude the possibility of contamination of Fluo3 fluorescence by the GFP fluorescence of the plasmid. We amplified the EGFP fragment by PCR using genomic DNA derived from each mutant clone and detected amplification of EGFP bands in several clones (Supplementary Fig. 5A). However, 

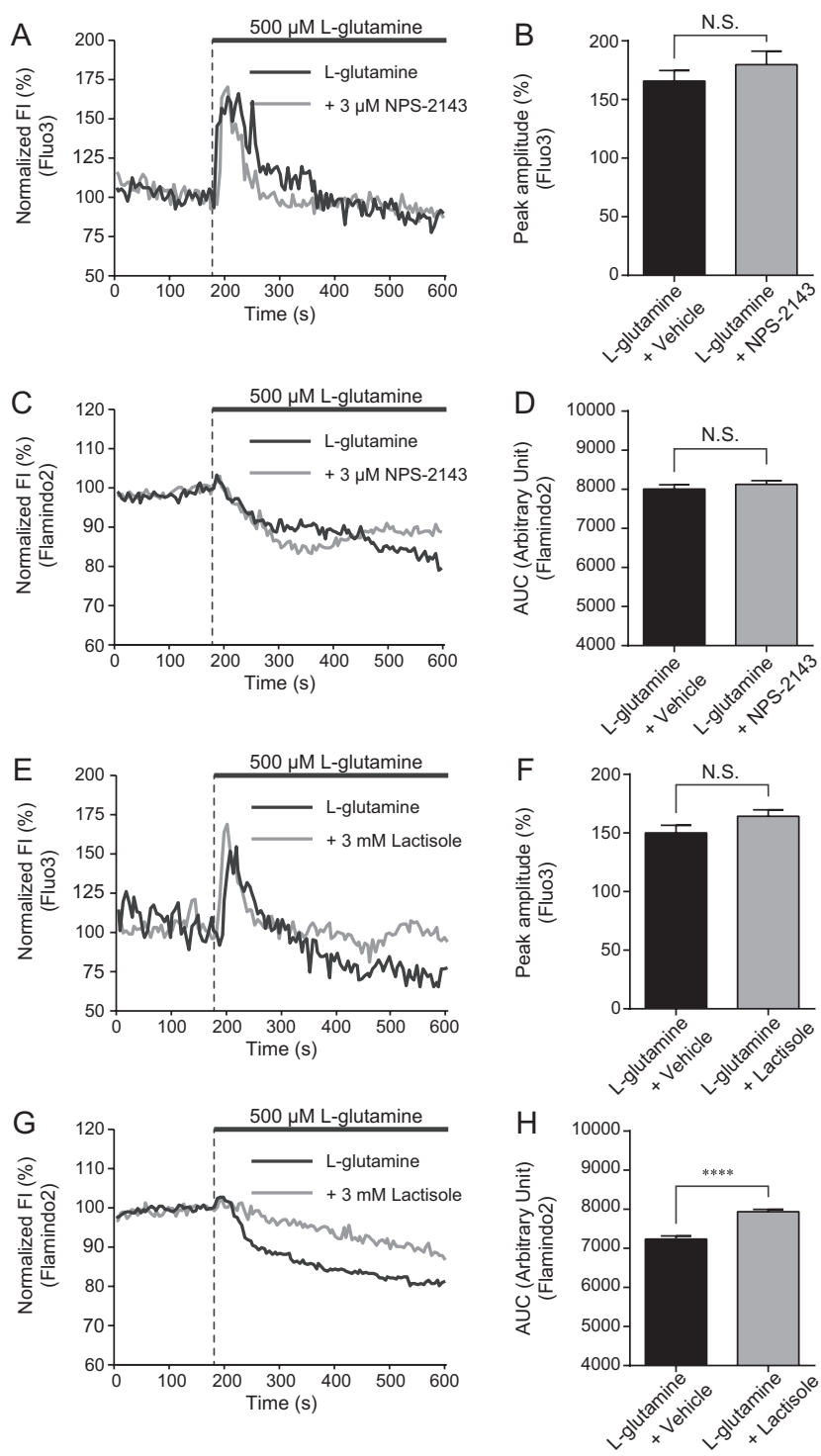

\section{Figure 2}

Role of CaSR and GPRC6A, and TAS1R1 or TAS1R3 in L-glutamine-induced increase in $\left[\mathrm{Ca}^{2+}\right]_{i}$ and $[\mathrm{CAMP}]_{i}$. (A) Typical time course of fluorescence intensity (FI) of Fluo3 during application of $500 \mu \mathrm{M} \mathrm{L-glutamine} \mathrm{with} 3 \mu \mathrm{M}$ NPS-2143. (B) Peak amplitude calculated from the Fl of Fluo3 by application of $500 \mu \mathrm{M}$ L-glutamine with $3 \mu \mathrm{M}$ NPS-2143; N $\geq 30$ cells from three independent experiments; Welch's $t$ test. (C) Typical time course of $\mathrm{Fl}$ of Flamindo2 during application of $500 \mu \mathrm{M} \mathrm{L}$-glutamine with $3 \mu \mathrm{M}$ NPS-2143. (D) Area under curve (AUC) calculated from the Fl of Flamindo2 by application of $500 \mu \mathrm{M}$ L-glutamine with $3 \mu \mathrm{M}$ NPS-2143. $N \geq 13$ cells from three independent experiments; Welch's $t$ test. (E) Typical time course of Fl of Fluo3 during application of $500 \mu \mathrm{M}$ L-glutamine with $3 \mathrm{mM}$ lactisole. (F) Peak amplitude calculated from the $\mathrm{Fl}$ of Fluo3 by application of $500 \mu \mathrm{M} \mathrm{L-glutamine} \mathrm{with} 3 \mathrm{mM}$ lactisole; $\mathrm{N} \geq 26$ cells from three independent experiments; Welch's $t$ test. (G) Typical time course of Fl of Flamindo2 during application of $500 \mu \mathrm{M}$ L-glutamine with $3 \mathrm{mM}$ lactisole. (H) Area under curve (AUC) calculated from the Fl of Flamindo2 by application of $500 \mu \mathrm{M}$ L-glutamine with 3 $\mathrm{mM}$ lactisole; $\mathrm{N} \geq 22$ cells from $\geq 3$ independent experiments; Welch's $t$ test. Data presented as mean \pm S.E.M. N.S., not significant; $* P<0.05$; $* * P<0.01 ; * * * P<0.001 ; * * * * P<0.0001$ we did not find any EGFP signals in any of the clones that showed EGFP bands by imaging analysis (Supplementary Fig. 5B). We thus investigated L-glutamine-induced GLP-1 secretion by TAS1R1- or TAS1R3- $\Delta$ C GLUTag cells using ELISA. L-glutamine-induced GLP-1 secretion was significantly lower in TAS1R3- $\Delta$ C GLUTag cells (Fig. 4A). However, mutant TAS1R1 had no effect on L-glutamineinduced GLP-1 secretion.

Next, we investigated L-glutamine-induced increase in $\left[\mathrm{Ca}^{2+}\right]_{\mathrm{i}}$ and $[\mathrm{CAMP}]_{\mathrm{i}}$ using other additional TAS1R1or TAS1R3- $\Delta \mathrm{C}$ GLUTag cell lines (Supplementary Figs 6 and 7). As expected, L-glutamine induced an increase in both $\left[\mathrm{Ca}^{2+}\right]_{\mathrm{i}}$ and $[\mathrm{CAMP}]_{\mathrm{i}}$ in TAS1R1- $\Delta \mathrm{C}$ GLUTag cell lines (Fig. 4B, C and Supplementary Fig. 8). Of note, the $\left[\mathrm{Ca}^{2+}\right]_{\mathrm{i}}$ elevation was impaired in one TAS1R3- $\Delta \mathrm{C}$ cell line (\#2), which was inconsistent with the result of lactisole treatment. The $[\mathrm{CAMP}]_{\mathrm{i}}$ elevation was impaired in two of the three TAS1R3- $\Delta$ C GLUTag cell lines (\#1 and \#2). These findings suggested that TAS1R3 is important for the $[\mathrm{cAMP}]_{\mathrm{i}}$ increase, which is consistent with the results of lactisole treatment; however, the dynamics of $\left[\mathrm{Ca}^{2+}\right]_{\mathrm{i}}$ and $[\mathrm{cAMP}]_{\mathrm{i}}$ were different in each TAS1R3- $\Delta \mathrm{C}$ cell line.

\section{Discussion}

We demonstrated the mechanisms of the L-glutamineinduced increase in $\left[\mathrm{Ca}^{2+}\right]_{\mathrm{i}}$ and $[\mathrm{cAMP}]_{\mathrm{i}}$ related to GLP-1 secretion (Fig. 5). L-glutamine induced GLP-1 secretion from GLUTag cells and triggered an increase in both

A

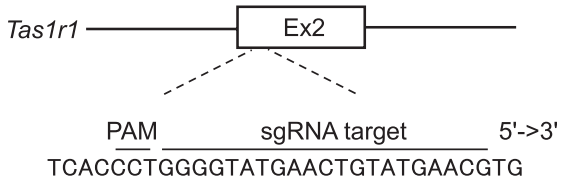

Control \#1

allele 1 TCACCCTGGG--ATGAACTGTATGAACGTG allele 2 TCACCCTGG------ACTGTATGAACGTG

(2bp del / 7 bp del)

B

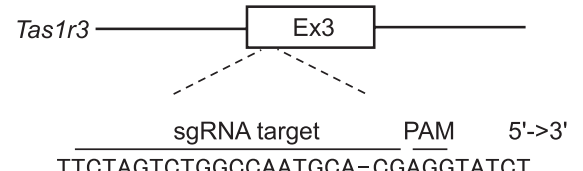

Control \#1

TTCTAGTCTGGCCAATGCA-CGAGGTATCT

TAS1R3-AC \#1 allele 1 TTCTAGTCTGGCCAATGCACCGAGGTATCT allele 2 TTCTAGTCTGGCCAATGCACCGAGGTATCT

(Homo 1 bp ins)

Figure 3

Establishment of homozygous TAS1R1- and TAS1R3- $\triangle C$ GLUTag cell lines. (A and B) Genome sequences of TAS1R1- (A) and TAS1R3- (B) $\triangle C$ GLUTag cells. PAM, protospacer adjacent motif sequence; sgRNA, single guide RNA; bp, base pairs; del, deletion; ins, insertion. 

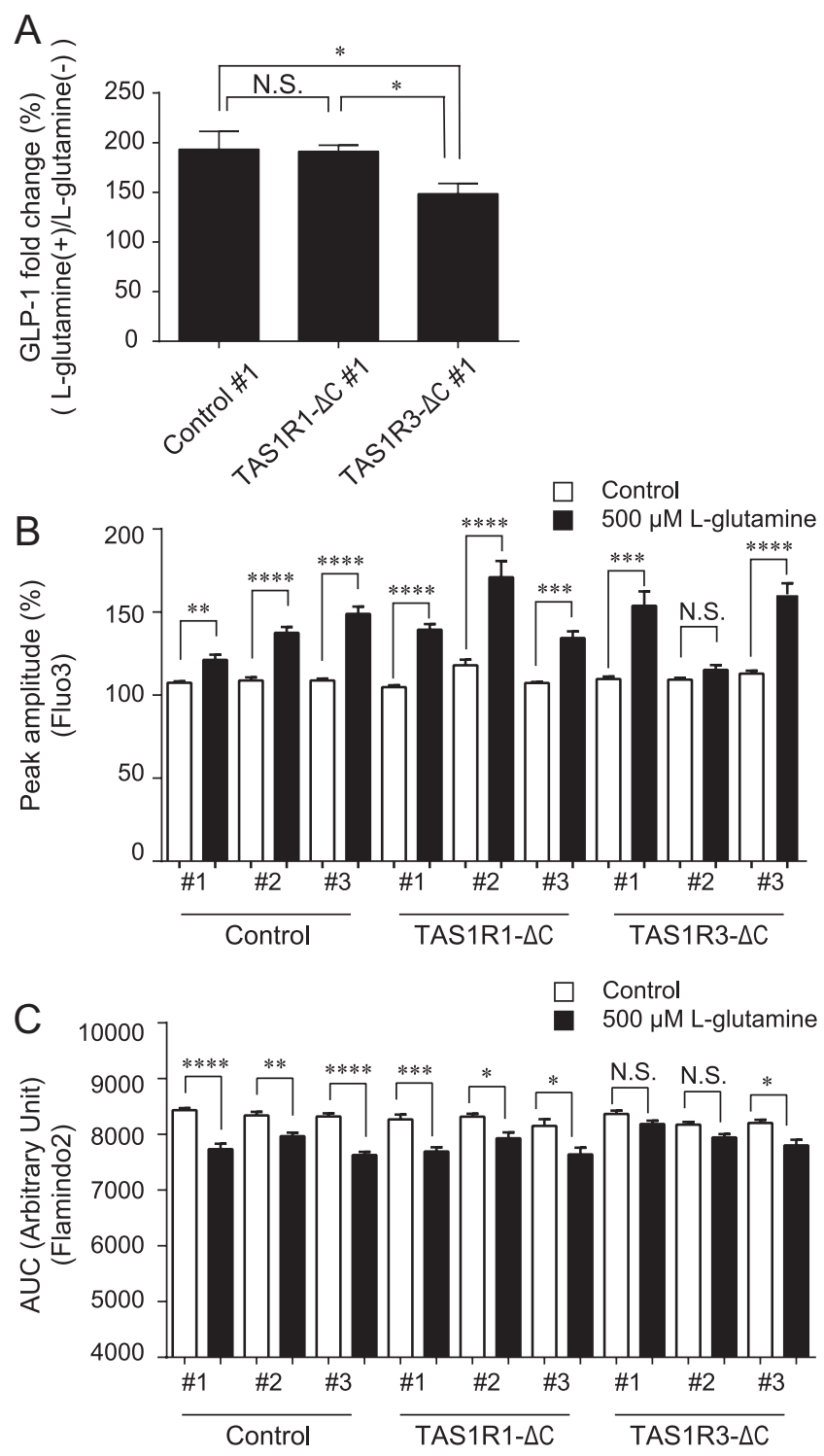

Figure 4

Examination of the involvement of TAS1R1 and TAS1R3 in GLP-1 secretion using homozygous TAS1R1 - or TAS1R3- $\triangle C$ GLUTag cells. (A) Results of ELISA showing fold-change of secreted GLP-1 in genome-edited GLUTag cells after the application of $500 \mu \mathrm{M} \mathrm{L-glutamine.} \mathrm{The} \mathrm{data} \mathrm{are} \mathrm{from} \mathrm{seven}$ trials from two experiments; One-way ANOVA multiple comparison test. (B) Peak amplitude calculated from the fluorescence intensity (FI) of Fluo3 by $500 \mu \mathrm{M}$ L-glutamine in control, TAS1R1- $\Delta \mathrm{C}$, and TAS1R3- $\Delta C$ GLUTag cells; $N \geq 20$ cell from $\geq 4$ independent experiments. Welch's $t$ test. The $P$ values were calculated by Bonferroni correction. (C) Area under curve (AUC) calculated from the Fl of Flamindo2 by application of $500 \mu \mathrm{M}$ L-glutamine in control, TAS1R1- $\Delta C$, and TAS1R3- $\Delta$ C GLUTag cells; N $\geq 13$ cells from $\geq 4$ independent experiments; Welch's $t$ test. The $P$ values were calculated by Bonferroni correction. Data presented as mean \pm S.E.M. N.S., not significant; $* P<0.05 ; * * P<0.01 ; * * * P<0.001 ; * * * * P<0.0001$.

$\left[\mathrm{Ca}^{2+}\right]_{\mathrm{i}}$ and $[\mathrm{cAMP}]_{\mathrm{i}}$. We suggest that sodium-coupled L-glutamine transporters regulate the L-glutamineinduced increase in $\left[\mathrm{Ca}^{2+}\right]_{\mathrm{i}}$ via VDCCs following $\mathrm{Na}^{+}$ influx. The pharmacological experiments revealed that the L-glutamine-induced increase in $\left[\mathrm{Ca}^{2+}\right]_{\mathrm{i}}$ and $[\mathrm{cAMP}]_{\mathrm{i}}$ levels was regulated via amino acid-sensitive GPCRs including TAS1R3.

In a previous study, human TAS1R3 were shown to exhibit sensitivity to lactisole in contrast to murine TAS1R3. This was attributable to specific amino acid residues in mouse and rat TAS1R3 that are critical for lactisole insensitivity; when those residues are mutated to human ones, they acquire lactisole sensitivity (Jiang et al. 2005). Another animal study showed that lactisole has little effect on sweet receptor, a heterodimer of TAS1R2 and TAS1R3 (Sclafani \& Pérez 1997). In this study, even higher concentration of lactisole had little effect on sucrose preference in rats. Conversely, although the sensitivity of murine TAS1R3 to lactisole was less than that of human TAS1R3, murine TAS1R3 was sensitive to high concentration of lactisole (Hamano et al. 2015). Furthermore, the present study provides evidence of the sensitivity of murine TAS1R3 to lactisole.

We speculate that the mouse TAS1R3 is insensitive to lactisole when combined with TAS1R2, typically in the tongue. Jiang et al. and Winning et al. found no inhibitory effect of lactisole on HEK293 cells with equal expressions of murine TAS1R2 and TAS1R3 (Jiang et al. 2005, Winnig et al. 2005). Sclafani et al. also showed the lack of sensitivity of the sweet receptor to lactisole (Sclafani \& Pérez 1997). On the other hand, Hamano et al. (Hamano et al. 2015) and the present study used the pancreatic $\beta$ cell line MIN6 and GLUTag cells, respectively, which dominantly express endogenous murine TAS1R3 compared to TAS1R2.

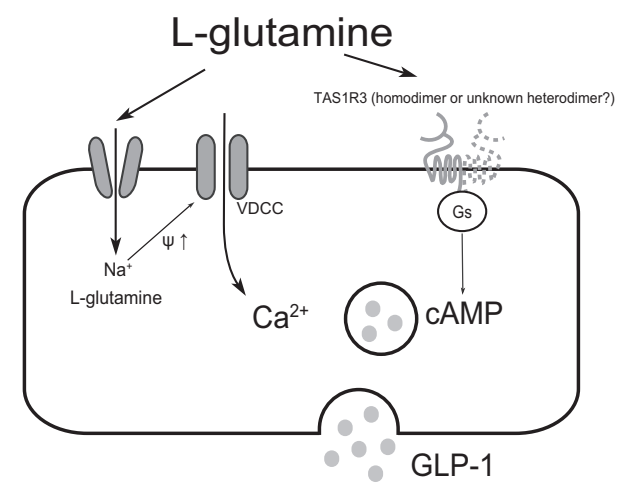

Figure 5

Schematic model of L-glutamine-induced secretion of GLP-1 by GLUTag cells. L-glutamine promotes the secretion of GLP-1 from GLUTag cells via elevation of $\left[\mathrm{Ca}^{2+}\right]_{i}$ and $[\mathrm{CAMP}]_{i}$ levels. Uptake of L-glutamine through sodium-dependent L-glutamine transporters causes membrane depolarization and induces $\mathrm{Ca}^{2+}$ influx via voltage-dependent $\mathrm{Ca}^{2+}$ channels (VDCCS). CAMP is produced by $\mathrm{G}_{\mathrm{s}}$ signaling pathway via TAS1R3, which may act as a homodimer or a heterodimer with an unknown GPCR without conjugation to TAS1R1 as the umami receptor. 
As mentioned below, TAS1R3 of MIN6 and GLUTag cells may form a homodimer or a heterodimer with other GPCRs and become at least partially sensitive to lactisole, unlike TAS1R3 in HEK293 cells and rats shown in the previous reports (Sclafani \& Pérez 1997, Jiang et al. 2005, Winnig et al. 2005). Further studies are required to validate this hypothesis.

In a recent study, treatment of MIN6 cells with lactisole was shown to suppress artificial sweetenerinduced increase in $\left[\mathrm{Ca}^{2+}\right]_{\mathrm{i}}$ level but not that of $[\mathrm{cAMP}]_{\mathrm{i}}$ (Hamano et al. 2015). However, we found that treatment of GLUTag cells with lactisole suppressed L-glutamateinduced increase in $[\mathrm{cAMP}]_{i}$ but not that of $\left[\mathrm{Ca}^{2+}\right]_{i}$ (Fig. 2). We speculate that MIN6 and GLUTag cells have variable dimerization patterns of TAS1R3. While Hamano et al. proposed that TAS1R3 forms a homodimer acting as a $\mathrm{G}_{\mathrm{q}}$-coupled sweet receptor, we speculate that TAS1R3 in GLUTag cells acts as a L-glutamine receptor, probably in combination with TAS1R3 itself or an unknown GPCR. The expression of Tas1r3 in intestinal cells is reported to be higher than that of Tas1r1 and Tas1r2, which form heterodimers with TAS1R3 (Reimann et al. 2008). Therefore, it is likely that TAS1R3 forms a homodimer or an unknown heterodimer that includes TAS1R3 coupled with $G_{s}$. Further investigation into the characteristics of TAS1R3, especially the dimerization kinetics, will help understand the significance of sweetener and amino acid receptors.

We observed that the increase in $\left[\mathrm{Ca}^{2+}\right]_{\mathrm{i}}$ was inhibited by treatment with low $\left[\mathrm{Na}^{+}\right]$, but not by treatment with NPS-2143 (Figs 1D and 2A). These results suggest that sodium-coupled L-glutamine transporters play an important role in evoking the increase in $\left[\mathrm{Ca}^{2+}\right]_{\mathrm{i}}$. We also found that NPS-2143 and lactisole did not suppress basal $\left[\mathrm{Ca}^{2+}\right]_{\mathrm{i}}$ and $[\mathrm{cAMP}]_{\mathrm{i}}$, or the high $\mathrm{K}^{+}$-induced increase in $\left[\mathrm{Ca}^{2+}\right]_{\mathrm{i}}$ and Fsk-induced increase in $[\mathrm{cAMP}]_{\mathrm{i}}$, respectively; this suggests a specific inhibitory effect of lactisole on [cAMP $_{\mathrm{i}}$ (Supplementary Fig. 3).

We developed TAS1R1- and TAS1R3- $\Delta \mathrm{C}$ GLUTag cells using the CRISPR/Cas9 system and found that the increase in $\left[\mathrm{Ca}^{2+}\right]_{\mathrm{i}}$ and $[\mathrm{CAMP}]_{\mathrm{i}}$ were not impaired in TAS1R1- $\Delta$ C GLUTag cells (Fig. 4B). TAS1R1 and TAS1R3 form a heterodimer (umami receptor) coupled with gustducin, which decreases $[\mathrm{cAMP}]_{\mathrm{i}}$. Because the $[\mathrm{cAMP}]_{\mathrm{i}}$ dynamics of TAS1R1- $\Delta$ C GLUTag cells were not impaired, we suggest that the umami receptor is not important for the L-glutamine-induced increase in $[\mathrm{cAMP}]_{\mathrm{i}}$. On the other hand, two of the three TAS1R3- $\Delta$ C GLUTag cell lines did not exhibit an increase in $[\mathrm{cAMP}]_{\mathrm{i}}$ (Fig. 4C). Therefore, we suggest that TAS1R3 is important for the
L-glutamine-induced increase in $[\mathrm{cAMP}]_{\mathrm{i}}$ and that a homodimer of TAS1R3 or a heterodimer of TAS1R3 and an unknown receptor might be coupled with $G_{s}$ protein. However, one of the three TAS1R3- $\Delta$ C cell lines exhibited cAMP response to L-glutamine; this suggests the existence of alternative mechanisms of increase in $[\mathrm{cAMP}]_{i}$ in GLUTag cells, which are independent of TAS1R3.

The TAS1R3- $\Delta$ C GLUTag cell line in the present study displayed varied $\left[\mathrm{Ca}^{2+}\right]_{\mathrm{i}}$ and $[\mathrm{cAMP}]_{\mathrm{i}}$ responses to L-glutamine stimulation. Assuming that this variability may be attributable to off-target mutations due to CRISPR/Cas9 system, we investigated the sequences of the top five candidate loci of off-target mutations predicted by gRNA design tools. However, we did not find any offtarget mutations in TAS1R1- or TAS1R3- $\Delta$ C GLUTag cells (Supplementary Figs 9 and 10). The diversity may be attributable to other unexpected off-target mutations. We previously reported unexpected off-target mutations in a genome-edited mouse line generated by the CRISPR/Cas9 system (Nakajima et al. 2016). Furthermore, several cell lines that were cloned, displayed different characteristics owing to the single cell cloning step; this may be another possible reason for the diversity of TAS1R3- $\Delta$ C GLUTag cells. Further analyses are necessary using other cloned cell lines to validate the reproducibility of the $\left[\mathrm{Ca}^{2+}\right]_{\mathrm{i}}$ and $[\mathrm{cAMP}]_{\mathrm{i}}$ responses in TAS1R3- $\Delta \mathrm{C}$ GLUTag cells.

Unexpectedly, we found that the Cas9-GFP plasmids may have possibly been inserted into genomic DNA in 4 of 9 GLUTag cell lines treated with CRISPR/ Cas9. Such unexpected insertions of plasmids may damage unrelated genes; therefore, due caution should be exercised while interpreting the results of genetically modified cell lines. Hence, we emphasize the need to check for potential genomic insertion of plasmids during establishment of mutant cell lines by single cell cloning using CRISPR/Cas9.

In the present study, we could not investigate L-glutamine-induced GLP-1 secretion by ELISA under conditions of pharmacological experiments; this was because prolonged exposure of GLUTag cells to antagonists, which is a necessary step for ELISA, may affect the ability of cells to secrete GLP-1. The mechanisms of L-glutamineinduced GLP-1 secretion have not been investigated in vivo. Thus, further studies are needed to fully elucidate the mechanisms of GLP-1 secretion.

Supplementary materials

This is linked to the online version of the paper at https://doi.org/10.1530/ JME-19-0260. 


\section{Declaration of interest}

The authors declare that there is no conflict of interest that could be perceived as prejudicing the impartiality of the research reported.

\section{Funding}

This work was supported by a Grant-in-aid for Scientific Research (26291018 to K O and 26460289, 17K08529, and $18 \mathrm{H} 04607$ to T T) from the Ministry of Education, Culture, Sports, Science and Technology of Japan, The Precise Measurement Technology Promotion Foundation (to T T), and the NAKATANI FOUNDATION (to T T).

\section{Author contribution statement}

$\mathrm{K} \mathrm{O}$, Tet $\mathrm{K}$, and $\mathrm{T} T$ designed the general concept. $\mathrm{T} \mathrm{N}$ and $\mathrm{K} \mathrm{H}$ wrote the original draft. $\mathrm{K} \mathrm{O}$, Tet $\mathrm{K}$, and $\mathrm{T} T$ edited and completed the manuscript. $\mathrm{T}$ $\mathrm{N}$ designed and performed the experiments to generate mutant cell lines. $\mathrm{K} \mathrm{H}$ conducted the imaging analysis of mutant cell lines. Tai K performed the pharmacological experiments and RT-PCR to validate the expression of each GPCR. M T measured the amount of GLP-1 by ELISA. J K and M G provided BIM-46187. K N and Tad K supervised the experiment to generate mutant cell lines.

\section{Acknowledgments}

The authors would like to thank Dr Daniel Drucker for kindly providing GLUTag cells, the Research Resources Division of RIKEN and Crimson Interactive Pvt. Ltd for English correction.

\section{References}

Ayoub MA, Damian M, Gespach C, Ferrandis E, Lavergne O, De Wever O, Banères JL, Pin JP \& Prévost GP 2009 Inhibition of heterotrimeric $\mathrm{G}$ protein signaling by a small molecule acting on Galpha subunit. Journal of Biological Chemistry 284 29136-29145. (https://doi.org/10.1074/jbc.M109.042333)

de Heer J, Rasmussen C, Coy DH \& Holst JJ 2008 Glucagon-like peptide-1, but not glucose-dependent insulinotropic peptide, inhibits glucagon secretion via somatostatin (receptor subtype 2 ) in the perfused rat pancreas. Diabetologia 51 2263-2270. (https://doi. org/10.1007/s00125-008-1149-y)

Diakogiannaki E, Gribble FM \& Reimann F 2012 Nutrient detection by incretin hormone secreting cells. Physiology and Behavior 106 387393. (https://doi.org/10.1016/j.physbeh.2011.12.001)

Drucker DJ 2018 Mechanisms of action and therapeutic application of glucagon-like peptide-1. Cell Metabolism 27 740-756. (https://doi. org/10.1016/j.cmet.2018.03.001)

Drucker DJ, Habener JF \& Holst JJ 2017 Discovery, characterization, and clinical development of the glucagon-like peptides. Journal of Clinical Investigation 127 4217-4227. (https://doi.org/10.1172/JCI97233)

Eng J, Kleinman WA, Singh L, Singh G \& Raufman JP 1992 Isolation and characterization of exendin-4, an exendin- 3 analogue, from Heloderma suspectum venom. Further evidence for an exendin receptor on dispersed acini from guinea pig pancreas. Journal of Biological Chemistry 267 7402-7405.

Feng X, Zhong S, Yang J, Wang Y \& Liu J 2013 Effects on glucagon-like peptide-1 secretion by distal ileal administration of nutrients. Obesity Surgery 23 1774-1782. (https://doi.org/10.1007/s11695-013-1021-0)

Friedlander RS, Moss CE, Mace J, Parker HE, Tolhurst G, Habib AM, Wachten S, Cooper DM, Gribble FM \& Reimann F 2011 Role of phosphodiesterase and adenylate cyclase isozymes in murine colonic glucagon-like peptide 1 secreting cells. British Journal of Pharmacology 163 261-271. (https://doi.org/10.1111/j.1476-5381.2010.01107.x)

Gribble FM, Williams L, Simpson AK \& Reimann F 2003 A novel glucose-sensing mechanism contributing to glucagon-like peptide-1 secretion from the GLUTag cell line. Diabetes 52 1147-1154. (https:// doi.org/10.2337/diabetes.52.5.1147)

Hamano K, Nakagawa Y, Ohtsu Y, Li L, Medina J, Tanaka Y, Masuda K, Komatsu M \& Kojima I 2015 Lactisole inhibits the glucose-sensing receptor T1R3 expressed in mouse pancreatic beta-cells. Journal of Endocrinology 226 57-66. (https://doi.org/10.1530/JOE-15-0102)

Harada K, Kitaguchi T, Kamiya T, Aung KH, Nakamura K, Ohta K \& Tsuboi T 2017 Lysophosphatidylinositol-induced activation of the cation channel TRPV2 triggers glucagon-like peptide-1 secretion in enteroendocrine L cells. Journal of Biological Chemistry 29210855 10864. (https://doi.org/10.1074/jbc.M117.788653)

Harada K, Sada S, Sakaguchi H, Takizawa M, Ishida R \& Tsuboi T $2018 a$ Bacterial metabolite S-equol modulates glucagon-like peptide-1 secretion from enteroendocrine L cell line GLUTag cells via actin polymerization. Biochemical and Biophysical Research Communications 501 1009-1015. (https://doi.org/10.1016/j.bbrc.2018.05.100)

Harada K, Sakaguchi H, Sada S, Ishida R, Hayasaka Y \& Tsuboi T $2018 b$ Bitter tastant quinine modulates glucagon-like peptide- 1 exocytosis from clonal GLUTag enteroendocrine L cells via actin reorganization. Biochemical and Biophysical Research Communications 500 723-730. (https://doi.org/10.1016/j.bbrc.2018.04.143)

Hsu TM, Noble EE, Liu CM, Cortella AM, Konanur VR, Suarez AN, Reiner DJ, Hahn JD, Hayes MR \& Kanoski SE 2018 A hippocampus to prefrontal cortex neural pathway inhibits food motivation through glucagon-like peptide-1 signaling. Molecular Psychiatry 23 1555-1565. (https://doi.org/10.1038/mp.2017.91)

Janssen S \& Depoortere I 2013 Nutrient sensing in the gut: new roads to therapeutics? Trends in Endocrinology and Metabolism 24 92-100. (https:// 10.1016/j.tem.2012.11.006)

Jiang P, Cui M, Zhao B, Liu Z, Snyder LA, Benard LM, Osman R, Margolskee RF \& Max M 2005 Lactisole interacts with the transmembrane domains of human T1R3 to inhibit sweet taste. Journal of Biological Chemistry 280 15238-15246. (https://doi. org/10.1074/jbc.M414287200)

Lamont BJ, Li Y, Kwan E, Brown TJ, Gaisano H \& Drucker DJ 2012 Pancreatic GLP-1 receptor activation is sufficient for incretin control of glucose metabolism in mice. Journal of Clinical Investigation 122 388-402. (https://doi.org/10.1172/JCI42497)

Margolskee RF, Dyer J, Kokrashvili Z, Salmon KS, Ilegems E, Daly K, Maillet EL, Ninomiya Y, Mosinger B \& Shirazi-Beechey SP 2007 T1R3 and gustducin in gut sense sugars to regulate expression of $\mathrm{Na}^{+-}$ glucose cotransporter 1. Proceedings of the National Academy of Sciences of the United States of America 104 15075-15080. (https:// doi.org/10.1073/pnas.0706678104)

Nakajima K, Kazuno AA, Kelsoe J, Nakanishi M, Takumi T \& Kato T 2016 Exome sequencing in the knockin mice generated using the CRISPR/Cas system. Scientific Reports 6 34703. (https://doi. org/10.1038/srep34703)

Nakamura T, Nakajima K, Ohnishi T, Yoshikawa T, Nakanishi M, Takumi T, Tsuboi T \& Kato T 2018 Quantitative evaluation of incomplete preweaning lethality in mice by using the CRISPR/Cas9 system. Scientific Reports 8 16025. (https://doi.org/10.1038/s41598-018-34270-5)

Nikolaev VO, Bünemann M, Hein L, Hannawacker A \& Lohse MJ 2004 Novel single chain cAMP sensors for receptor-induced signal propagation. Journal of Biological Chemistry 279 37215-37218. (https://doi.org/10.1074/jbc.C400302200)

Odaka H, Arai S, Inoue T \& Kitaguchi T 2014 Genetically-encoded yellow fluorescent cAMP indicator with an expanded dynamic range for dual-color imaging. PLOS ONE 9 e100252. (https://doi. org/10.1371/journal.pone.0100252)

Oya M, Kitaguchi T, Pais R, Reimann F, Gribble F \& Tsuboi T 2013 The G protein-coupled receptor family C group 6 subtype A (GPRC6A) https://jme.bioscientifica.com

https://doi.org/10.1530/JME-19-0260 (c) 2020 Society for Endocrinology Published by Bioscientifica Ltd. Printed in Great Britain 
receptor is involved in amino acid-induced glucagon-like peptide-1 secretion from GLUTag cells. Journal of Biological Chemistry 288 4513-4521. (https://doi.org/10.1074/jbc.M112.402677)

Reimann F, Habib AM, Tolhurst G, Parker HE, Rogers GJ \& Gribble FM 2008 Glucose sensing in L cells: a primary cell study. Cell Metabolism 8 532-539. (https://doi.org/10.1016/j.cmet.2008.11.002)

Richards P, Parker HE, Adriaenssens AE, Hodgson JM, Cork SC, Trapp S, Gribble FM \& Reimann F 2014 Identification and characterization of GLP-1 receptor-expressing cells using a new transgenic mouse model. Diabetes 63 1224-1233. (https://doi.org/10.2337/db13-1440)

Rodriquez de Fonseca F, Navarro M, Alvarez E, Roncero I, Chowen JA, Maestre O, Gómez R, Muñoz RM, Eng J \& Blázquez E 2000 Peripheral versus central effects of glucagon-like peptide-1 receptor agonists on satiety and body weight loss in Zucker obese rats. Metabolism: Clinical and Experimental 49 709-717. (https://doi. org/10.1053/meta.2000.6251)

Sclafani A \& Pérez C 1997 Cypha $^{\mathrm{TM}}$ [propionic acid, 2-(4-methoxyphenol) salt] inhibits sweet taste in humans, but not in rats. Physiology and Behavior 61 25-29. (https://doi.org/10.1016/s0031-9384(96)00316-2)

Smith EP, An Z, Wagner C, Lewis AG, Cohen EB, Li B, Mahbod P, Sandoval D, Perez-Tilve D, Tamarina N, et al. 2014 The role of beta cell glucagon-like peptide-1 signaling in glucose regulation and response to diabetes drugs. Cell Metabolism 19 1050-1057. (https:// doi.org/10.1016/j.cmet.2014.04.005)

Suzuki K, Akiyama M, Ishigaki K, Kanai M, Hosoe J, Shojima N, Hozawa A, Kadota A, Kuriki K, Naito M, et al. 2019 Identification of
28 new susceptibility loci for type 2 diabetes in the Japanese population. Nature Genetics 51 379-386. (https://doi.org/10.1038/ s41588-018-0332-4)

Tolhurst G, Heffron H, Lam YS, Parker HE, Habib AM, Diakogiannaki E, Cameron J, Grosse J, Reimann F \& Gribble FM 2012 Short-chain fatty acids stimulate glucagon-like peptide- 1 secretion via the G-protein-coupled receptor FFAR2. Diabetes 61 364-371. (https://doi. org/10.2337/db11-1019)

Tolhurst G, Zheng Y, Parker HE, Habib AM, Reimann F \& Gribble FM 2011 Glutamine triggers and potentiates glucagon-like peptide-1 secretion by raising cytosolic $\mathrm{Ca}^{2+}$ and cAMP. Endocrinology 152 405413. (https://doi.org/10.1210/en.2010-0956)

Villhauer EB, Brinkman JA, Naderi GB, Burkey BF, Dunning BE, Prasad K, Mangold BL, Russell ME \& Hughes TE 2003 1-[[(3-Hyd roxy-1-adamantyl)amino]acetyl]-2-cyano-(S)-pyrrolidine: a potent, selective, and orally bioavailable dipeptidyl peptidase IV inhibitor with antihyperglycemic properties. Journal of Medicinal Chemistry 46 2774-2789. (https://doi.org/10.1021/jm0300911)

Wellendorph P, Johansen LD \& Bräuner-Osborne H 2009 Molecular pharmacology of promiscuous seven transmembrane receptors sensing organic nutrients. Molecular Pharmacology 76 453-465. (https://doi.org/10.1124/mol.109.055244)

Winnig M, Bufe B \& Meyerhof W 2005 Valine 738 and lysine 735 in the fifth transmembrane domain of rTas1r3 mediate insensitivity towards lactisole of the rat sweet taste receptor. BMC Neuroscience 6 22. (https://doi.org/10.1186/1471-2202-6-22)

Received in final form 22 December 2019

Accepted 13 January 2020

Accepted Manuscript published online 15 January 2020
(C) 2020 Society for Endocrinology Published by Bioscientifica Ltd. Printed in Great Britain 